\title{
A DHT-Supported Piece Driven Overlay for P2P Live Gushing
}

\author{
G. Michael, B. Sundar Raj, G. Kavitha
}

\begin{abstract}
Peer-to-peer live streaming technologies allow a constricted source of data transmission to transmit a video that encourages a significant amount of customers. The primary objective of live gushing is to convey stream information to all customers previously their playback due date. Outline effectiveness is basically described by the spilling rate that can be managed, and by the postpone it takes for information to achieve customers from the source. Furthermore, a plan with high connection usage can accomplish high stream rates, supporting amazing video. As of recently, just tree-based plans have been appeared to accomplish near ideal rates, all items regarded, circumstances, leaving the investigation open as to the viable efficacy of completely unstructured methodologies based on job. We answer that inquiry by demonstrating that a painstakingly composed work based framework can accomplish near ideal stream rates In particular, in the context of a work-based count called DP / LU, we are executing and surveying a structure. Instead of tree-based diagrams, DP / LU utilizes an unstructured overlay that is less demanding to produce and extremely impenetrable to mix. Moreover, we recognize a few outline advancements which help enhance the rate and defer execution of work based frameworks. Our experiment evaluation shows that in a static scenario, our sketch achieves $95 \%$ of the most severe achievable flow speed and $90 \%$ under elevated agitate. This displays work-based outlines are an amazing choice for live spilling distributed versatile and powerful top notch. Live video spilling administrations are spreading rapidly finished the Internet. To tell the truth, many frameworks use basic gushing conventions that underuse uplinks from customers, squandering accessible transmission capacity. This problem will turn out to be more authentic as customers will demand top notch entertainment in the near future, increasing the necessary stream bitrates. This prompts the associated investigation: are tree-based plans going to exchange working schedules oriented on top-notch live video gushing? We trust that the appropriate response is no. To help this, we play out an examination which demonstrates that a precisely planned work based framework can accomplish close ideal rates and low dissemination delays.
\end{abstract}

\section{Keywords: Churn, Chunk, Utilization, video streaming.}

\section{INTRODUCTION}

Streaming media is sight and sound that an end-client is constantly acquired and familiar with. While a supplier is carried on. Stream indicates the route to transmitting media along these lines; the word insinuates the medium's motion operation rather than the medium itself. Video gushing is a one-by-one spill of packaging [1-5]. A client media player can

Revised Manuscript Received on August 22, 2019.

G.Michael, Department of CSE, Bharath Institute of Higher Education and Research, Chennai, Tamilnadu, India.

B. Sundar Raj, Department of CSE, Bharath Institute of Higher Education and Research, Chennai, Tamilnadu, India.

G. Kavitha, Department of CSE, Bharath Institute of Higher Education and Research, Chennai, Tamilnadu, India. start recording the information (for example, a movie) before the whole record is transferred Distinguishing transport method from the flowing media applies in particular to media correspondence frameworks, as most other transport buildings are either naturally streaming (for example, radio, TV) or usually non-streaming (for example, comics, video tapes, audio CDs).

\section{SYSTEM ANALYSIS}

\section{A. Existing system}

A structure's performance will corrupt and problem happens as a tremendous scale is created by the number of customers. The palatable spouting quality Live Streaming Service is not accessible to customers outcome, the overlay can offer celestial streaming of video. We use pleasant game theory to break down the motivating forces that should be provided to stable hubs to empower DHT-based procedures. We also suggest a centralized and streamlined algorithm for the selection of suppliers. In supervising churn and work-based devices, DCO is inferior to anything tree-based constructions in transmission threshold consumption and latency. More fundamentally, by combining chunk requesters and suppliers efficiently, it can take complete benefit of structure information transmission. The experiment findings indicate that in terms of scalability, accessibility, torpidity, and overhead, DCO increases the execution of mesh-based structures (draw and push) and tree-based structures. The exam goes about likewise confessing the hugeness of providing persuasive authority to invite centres to function as DHT-based institution coordinators and the significance of selecting piece suppliers with adequate bandwidth in knot delivery. We will think in our future how to get to DCO the tools that enhance tree-based approaches [6-8].

\section{B. PROPOSED SYSTEM}

A structure's performance will not degrade and even enhance as a significant scale is created by the number of clients. The Live Streaming Service with appealing spouting quality is accessible to customers under all framework circumstances including center point motion (i.e. churn). High-quality video streams with stringent ongoing execution requirements do not require video streams to be traded under time and data transmission restrictions. .It is not defenseless against stir and they take on a amount of natural benefits after Distributed hash construction occurs. The Live Streaming issue is stayed away from by utilizing a piece sharing calculation and a supplier choice algorithm. Since the execution among the upstream

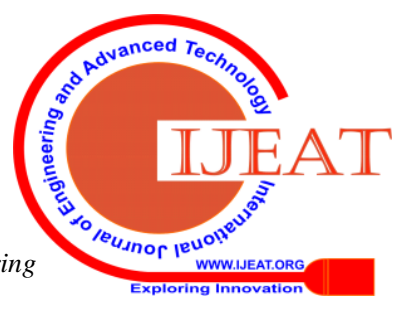


organizations is not limited by the base throughput, an improperly constructed Distributed hash framework can result in efficient transfer speed use and less deferral [9-12].

\section{TECHNICAL TERMS}

\section{A. Utilization}

Usage is the essential strategy by which resource execution is measured and business achievement decided. Essentially, it is a metric of the real income that funds earn against the prospective revenue that they might have gained [13].

\section{B. Live Stream}

Live stream recognized as Mogulus some time ago is a live flowing video phase that allows customers to view and interact video material through the internet using a PC.It offers a free advertisement upheld benefit and multi-layered premium administrations [14].

\section{Churn}

Agitate rate (some of the time called whittling down rate), in its broadest sense, is a measure of the number of people or things moving out of a collective over a particular timeframe. It is one of two essential factors that decide the enduring detail level of clients a business will bolster [15].

\section{Chunk}

A piece is a information segment used as portion of various sight and sound organisations, including PNG, IFF, MP3, and AVI. Each lump includes a header showing a few parameters (e.g. lump type, comments, estimate, etc.) In the center there are variable range data decoded from the parameters in the header by the program [16].

\section{E. Provider selection algorithm}

To manufacture a dynamic tree with top down diminishing hub data transmission for familiar stream, a facilitator DHT hub considers add up to transfer speed, accessible transmission capacity and buffering limit in doling out piece suppliers to requesters. A decentralized choice calculation is additionally proposed to empower lump suppliers and requesters to consequently coordinate independent from anyone else without depending on organizers [17].

\section{ALGORITHM DETAILS}

\section{A. Chunk Sharing Algorithm}

Using DHT job documented by lumps IDs, each node first reports its accessible parts to the DHT and asks the DHT to do so. For subsequent solicitation, the DHT maps the supplier and requests a comparison item to a similar supplier. Thus the irregularities of the stream are transferred along a dynamic tree that reduces the performance of the grid transmission from bottom down. [18].

\section{B. Provider selection algorithm}

In order to produce a dynamic tree with top-down diminishing hub data transmission for familiar stream, a DHT hub facilitator sees transferring velocity, available transmission capability, and buffering limits to dol out piece vendors to requestors. A decentralized choice calculation is additionally proposed to empower lump suppliers and requesters to consequently coordinate independent from anyone else without depending on organizers.

\section{RESULTS AND DISCUSSION}

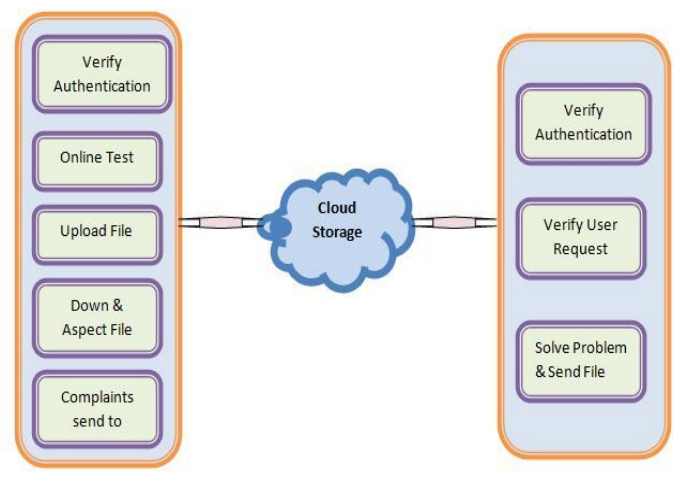

Modules: After cautious examination the framework has been distinguished to have the accompanying modules [19].

\section{A. Selecting the dynamic Peers}

Actuate customers who are interested in exchanging the records over the host with the aim that the other can use these files. The organisation should complete the initiation. The main node checks all the operation. Any client may be included in the manner to sharing after the review phase. The head checks the validation method. If the client has forgotten to stack his own subtle aspects then with the help of the administrator he can retrieve his points of concern. Outcome to the separate associate. In view of the score the further procedure can be done with the assistance of administrator [20].

\section{B. Transfer Files}

Following the start of the teaching exam, the further operation can be finished with the help of the administrator in perspective of the rating. If the rating is good then they may be entitled to pass documents. Naturally, record size will be calculated while the papers are being transferred. Document size can likewise be accounted for to the Admin. Transferred documents will be kept up by the administrator. He can see all clients documents [21].

\section{View File List}

In the wake of transferring the different Files, the confirmed and educated client has the rights to see the records transferred by the other verified client. Administrator has all rights all through the procedure and the administrator keep up protestations shape. The client can choose the other client to see the rundown of records transferred by him. At that point he sees the transferred documents and in addition downloads the records which were transferred by different clients $[22,23]$.

\section{Objections handover}

Consequent to survey the records exchanged by the customer. Exchanged archives can be seen by the pariah customer. In case the customer saw video is demolished or hurt then he can 
make protesting to the official as the records exchanged will be kept up by the administrator. The Complaints gave will be subsequently gotten by the manager and he can see the protesting gave [24-27].

\section{E. Unscrambling the complaints of User}

Subsequent to review the protestations by the administrator gave by the admin. He can unscramble the objections by giving the required documents. The client grumblings can be settled by transferring the required record to them by and by with the goal that the issue can be comprehended totally. Grumbling subtle elements will be kept up by the administrator to confirm the procedure in future. High-quality video gushing with stringent coherent execution requirements requires that video streams be traded under time limitations and information transmission limitations. It is susceptible to foment and they carry a amount of inalienable constraints after tree-based framework. If a parent leaves or fails, before the tree is repaired, his children can not get the live stream. The settled tree structure and stream bearing render it difficult to hold complete preferred bandwidth position effectively. Since the execution is limited by the base performance of the upstream affiliations, an inappropriately mounted tree can perform inefficient use of swap velocity and lengthy deferment [28-30].

\section{CONCLUSION}

In this document, we suggest a DHT-upheld piece oriented overlay that seeks greater scalability, greater openness, and low latency for P2P live gushing. Fragments of the scheme hash tree principle: a two-layer separate rated DHT-based infrastructure, an estimate of bump sharing, and a choice count of video providers. High adaptability is provided by the distinct leveled DHT-based infrastructure. The count of piece sharing provides organisation to bump the collection and disclosure of documents, which ensures high availability. Figuring the supplier choice allows complete use of the velocity of system return.

\section{REFERENCES}

1. Gowri Sankaran, B., Karthik, B. \& Vijayaragavan, S.P. 2019, "Weight ward change region plummeting change for square based image huffman coding", International Journal of Innovative Technology and Exploring Engineering, vol. 8, no. 10, pp. 4313-4316.

2. Gowri Sankaran, B., Karthik, B. \& Vijayaragavan, S.P. 2019, "Image compression utilizing wavelet transform", International Journal of Innovative Technology and Exploring Engineering, vol. 8, no. 10, pp. 4305-4308.

3. Kandavel, N. \& Kumaravel, A. 2019, "Offloading computation for efficient energy in mobile cloud computing", International Journal of Innovative Technology and Exploring Engineering, vol. 8, no. 10, pp. 4317-4320.

4. Vinoth, V.V. \& Kanniga, E. 2019, "Reversible data hiding in encrypting images-an system", International Journal of Engineering and Advanced Technology, vol. 8, no. 6, pp. 3051-3053.

5. Selvapriya, B. \& Raghu, B. 2019, "Pseudocoloring of medical images: A research", International Journal of Engineering and Advanced Technology, vol. 8, no. 6, pp. 3712-3716.

6. Senthil Kumar, K. \& Muthukumaravel, A. 2019, "Bi-objective constraint and hybrid optimizer for the test case prioritization", International Journal of Engineering and Advanced Technology, vol. 8, no. 6, pp. 3436-3448.

7. Kavitha, G., Priya, N., Anuradha, C. \& Pothumani, S. 2019, "Read-write, peer-to-peer algorithms for the location-identity split", International Journal of Innovative Technology and Exploring Engineering, vol. 8, no. 9 Special Issue 3, pp. 445-447.
8. Kaliyamurthie, K.P., Michael, G., Anuratha, C. \& Sundaraj, B. 2019 , "Certain improvements in alzheimer disease classification using novel fuzzy c means clustering for image segmentation", International Journal of Innovative Technology and Exploring Engineering, vol. 8, no. 9 Special Issue 3, pp. 599-604.

9. Kaliyamurthie, K.P., Sundarraj, B., Geo, A.V.A. \& Michael, G. 2019, "RIB: Analysis of I/O automata", International Journal of Innovative Technology and Exploring Engineering, vol. 8, no. 9 Special Issue 3, pp. 1019-1022.

10. Velvizhi, R., Rajabhushanam, C. \& Vidhya, S.R.S. 2019, "Opinion mining for travel route recommendation using Social Media Networks (Twitter)", International Journal of Innovative Technology and Exploring Engineering, vol. 8, no. 9 Special Issue 3, pp. 508-512.

11. Kavitha, R., Sangeetha, S. \& Varghese, A.G. 2019, "Human activity patterns in big data for healthcare applications", International Journal of Innovative Technology and Exploring Engineering, vol. 8, no. 9 Special Issue 3, pp. 1101-1103.

12. Pothumani, S., Anandam, A.K., Sharma, N. \& Franklin, S. 2019, "Extended VEOT framework - Implemented in a smart boutique", International Journal of Innovative Technology and Exploring Engineering, vol. 8, no. 9 Special Issue 3, pp. 762-767.

13. Kaliyamurthie, K.P., Michael, G., Krishnan, R.M.V. \& Sundarraj, B. 2019, "Pseudorandom techniques for the internet", International Journal of Innovative Technology and Exploring Engineering, vol. 8, no. 9 Special Issue 3, pp. 915-918.

14. Aravindasamy, R., Jeffrin Rajan, M., Rama, A. \& Kavitha, P. 2019, "Deep learning provisions in the matlab: Focus on CNN facility", International Journal of Innovative Technology and Exploring Engineering, vol. 8, no. 9 Special Issue 3, pp. 990-994

15. Theivasigamani, S., Linda, M. \& Amudha, S. 2019, "Object sensing and its identification \& motion sensing", International Journal of Innovative Technology and Exploring Engineering, vol. 8, no. 9 Special Issue 3, pp. 545-549.

16. Mary Linda, I., Vimala, D. \& Shanmuga Priya, K. 2019, "A methodology for the emulation of IPv4", International Journal of Innovative Technology and Exploring Engineering, vol. 8, no. 9 Special Issue 3, pp. 848-852.

17. Velvizhi, R., Priya, D.J., Vimala, D. \& Linda, I.M. 2019, "Increased routing algorithm for mobile adhoc networks", International Journal of Innovative Technology and Exploring Engineering, vol. 8, no. 9 Special Issue 3, pp. 1606-1608.

18. Sangeetha, S., Anuradha, C. \& Priya, N. 2019, "DNS in real world", International Journal of Innovative Technology and Exploring Engineering, vol. 8, no. 9 Special Issue 3, pp. 937-940.

19. Geetha, C., Vimala, D. \& Priya, K.S. 2019, "Constructing multi-processors and spreadsheets with SKIVE", International Journal of Innovative Technology and Exploring Engineering, vol. 8, no. 9 Special Issue 3, pp. 516-519.

20. Yugendhar, K., Sugumar, V. \& Kavitha, P. 2019, "A novel method of univac using fuzzy logic", International Journal of Innovative Technology and Exploring Engineering, vol. 8, no. 9 Special Issue 3, pp. 435-437.

21. Kaliyamurthie, K.P., Michael, G., Elankavi, R. \& Jijo, S.A. 2019, "Implementing aggregate-key for sharing data in cloud environment using cryptographic encryption", International Journal of Innovative Technology and Exploring Engineering, vol. 8, no. 9 Special Issue 3, pp. 957-959.

22. Jeffrin Rajan, M., Aravindasamy, R., Kavitha, P. \& Rama, A. 2019, "A novel method of object orientation variation in $\mathrm{C}++$ and java", International Journal of Innovative Technology and Exploring Engineering, vol. 8, no. 9 Special Issue 3, pp. 708-710.

23. Nayak, R., Dinesh, S. \& Thirunavukkarasu, S. 2019, "A novel method improvement of rapid miner for the data mining applications", International Journal of Innovative Technology and Exploring Engineering, vol. 8, no. 9 Special Issue 3, pp. 457-460

24. Sivaraman, K., Krishnan, R.M.V., Sundarraj, B. \& Sri Gowthem, S. 2019, "Network failure detection and diagnosis by analyzing syslog and SNS data: Applying big data analysis to network operations", International Journal of Innovative Technology and Exploring Engineering, vol. 8, no. 9 Special Issue 3, pp. 883-887.

25. Vimala, D., Linda, I.M. \& Priya, K.S. 2019, "Decoupling online algorithms from erasure coding in DNS", International Journal of Innovative Technology and Exploring Engineering, vol. 8, no. 9 Special Issue 3, pp. 950-953.

26. Rama, A., Kumaravel, A. \& Nalini, C. 2019, "Preprocessing medical images for classification using deep learning techniques",

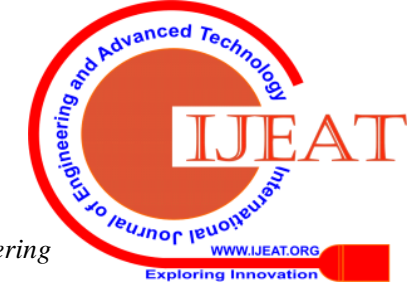


International Journal of Innovative Technology and Exploring Engineering, vol. 8, no. 9 Special Issue 3, pp. 711-716.

27. Sangeetha, S., Srividhya, S.R., Anita Davamani, K. \& Amudha, S. 2019,

"A procedure for avoid overrun error in universal synchronous asynchronous receiver transmitter (usart) by utilizing dummy join and interrupt latency method", International Journal of Innovative Technology and Exploring Engineering, vol. 8, no. 9 Special Issue 3, pp. 657-660.

28. Aravindasamy, R., Jeyapriya, D., Sundarajan, B. \& Sangeetha, S. 2019, "Data duplication in cloud for optimal performance and security", International Journal of Innovative Technology and Exploring Engineering, vol. 8, no. 9 Special Issue 3, pp. 1156-1158.

29. Aravindasamy, R., Jeffrin Rajan, M., Sugumar, V. \& Kavitha, P. 2019, "A novel method on developing superblocks and the transistor using apodryal", International Journal of Innovative Technology and Exploring Engineering, vol. 8, no. 9 Special Issue 3, pp. 982-985.

30. Sasikumar, C.S. \& Kumaravel, A. 2019, "E-learning attributes selection through rough set theory and data mining", International Journal of Innovative Technology and Exploring Engineering, vol. 8, no. 10, pp. 3920-3924.

\section{AUTHORS PROFILE}

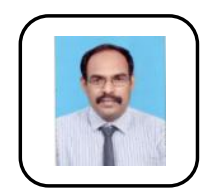

G.Michael Associate Professor, Department of Computer Science \& Engineering, Bharath Institute of Higher Education and Research, Chennai, India

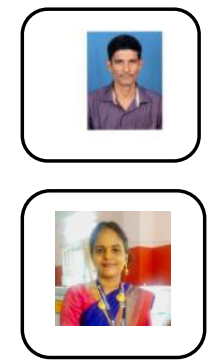

B. Sundar Raj Assistant Professor, Department of Computer Science \& Engineering, Bharath Institute of Higher Education and Research, Chennai, India

G. Kavitha Assistant Professor, Department of Computer Science \& Engineering, Bharath Institute of Higher Education and Research, Chennai, India 